\title{
Erratum to: Ultrasensitive determination of bisphenol $A$ and its chlorinated derivatives in urine using a high-throughput UPLC-MS/MS method
}

\author{
Claire Grignon $^{1,2} \cdot$ Nicolas Venisse ${ }^{1,2} \cdot$ Steeve Rouillon ${ }^{1,2} \cdot$ Bertrand Brunet $^{1,2}$. \\ Astrid Bacle $^{1,2} \cdot$ Sarah Thevenot ${ }^{1,2} \cdot$ Virginie Migeot ${ }^{1,2}$ - Antoine Dupuis ${ }^{1,2}$
}

Received: 29 January 2016 / Accepted: 29 January 2016 / Published online: 12 February 2016

(C) Springer-Verlag Berlin Heidelberg 2016

Erratum to: Anal Bioanal Chem

DOI 10.1007/s00216-015-9288-8

The original version of this article unfortunately contained a mistake. The family name of the first author is incorrect. The correct family name is Grignon. The original article was corrected.

The online version of the original article can be found at http://dx.doi.org/ 10.1007/s00216-015-9288-8.

\footnotetext{
Antoine Dupuis

antoine.dupuis@univ-poitiers.fr
}

1 CNRS-UMR 7285 IC2MP, Department of Analytical Chemistry, Pharmaceutics and Epidemiology, School of Medicine and Pharmacy, University of Poitiers, 6 rue de la Milétrie, 86034 Poitiers CEDEX, France

2 Biology-Pharmacy-Public Health Department, University Hospital of Poitiers, 2 rue de la Milétrie, 86021 Poitiers CEDEX, France 